\title{
Coupling River Concentration Simulations with a Toxicokinetic Model Effectively Predicts the Internal Concentrations of Wastewater-Derived Micropollutants in Field Gammarids
}

Maricor J. Arlos, * Florian Schürz, Qiuguo Fu, Benedikt B. Lauper, Christian Stamm, and Juliane Hollender*

Cite This: Environ. Sci. Technol. 2020, 54, 1710-1719

Read Online

\section{ACCESS |}

Џlll Metrics \& More

Article Recommendations

Supporting Information

ABSTRACT: Although the exposure assessment of wastewaterderived micropollutants via chemical, bioanalytical, and modeling methods in environmental compartments is becoming more frequent, the whole-body burden (i.e., internal concentrations) in nontarget organisms is rarely assessed. An understanding of the internal concentration fluctuation is especially important when exploring the mechanistic linkage between exposure and effects. In this study, we coupled a simple river model with a first-order toxicokinetic (TK) model to predict the concentrations of wastewater-derived micropollutants in freshwater invertebrates (Gammarus spp.). We applied Monte Carlo simulations and conducted laboratory experiments to account for the uncertain input data and the lack of uptake/depuration rate constants required

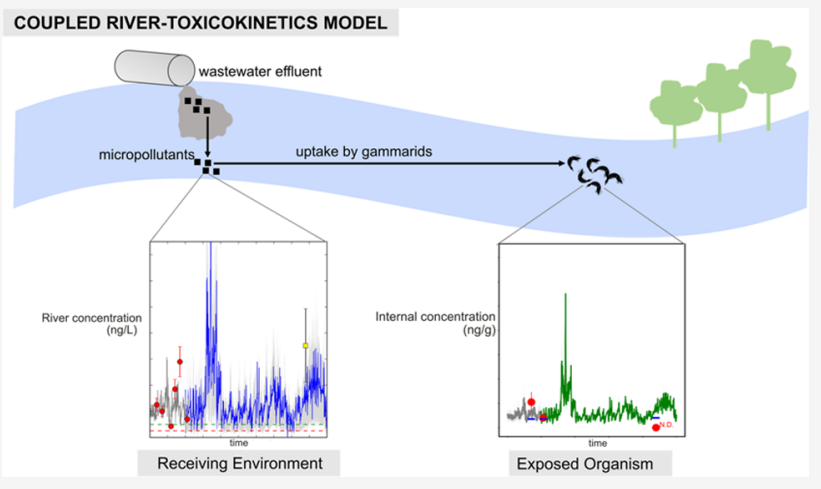
for the TK model. The internal concentrations in field gammarids were predicted well, and the estimates varied only by a factor of 0.1-1.9. Fast equilibrium may also be assumed such that bioconcentration factors (BCFs) are used together with the daily river dilution patterns to predict internal concentrations. While this assumption is suitable for compounds observed in our experiment to reach the steady state within $48 \mathrm{~h}$ in gammarids, the model overpredicted the concentrations of substances that reach this condition after longer periods. Nevertheless, this approach provides conservative estimates and simplifies the coupling of models as BCFs are slightly more accessible than the rate constants. However, if one is interested in a more detailed exposure information (e.g., peak concentration and the whole-body burden recovery after a spill), then the nonsteady-state formulation should be employed.

\section{INTRODUCTION}

Wastewater-derived micropollutants are a diverse classification of compounds that include pharmaceuticals, personal care products, and plant protection products. They are present in the environment at extremely low concentrations, are ubiquitous in the aquatic environment, and can potentially impact the development, behavior, and reproduction of aquatic organisms. $^{1-3}$ In recent years, the detection of wastewaterderived micropollutants in surface waters has become a part of chemical monitoring programmes as in the case of the European Commission's Watch List of substances that is monitored in European Union (EU) surface waters (Decision 2015/495/EU ${ }^{4}$ ). However, the impact of their fluctuating concentrations on exposed nontarget organisms is rarely characterized. ${ }^{5}$ Evaluating the time course of a contaminant within an organism in response to changing environmental concentrations can be done via toxicokinetics (TK), ${ }^{6}$ a process typically studied in the laboratory to determine bioaccumulation.
There are well-established contaminant fate and transport models that can be used to estimate the temporal and spatial distribution of wastewater-derived micropollutants in surface waters. ${ }^{7}$ However, TK models remain underused in exposure science. ${ }^{8}$ They are often employed independently of fate and transport models (and vice versa), making them difficult to coherently link environmental exposure fluctuations with the internal concentration dynamics in target organisms. When these modeling techniques are combined, they become an indispensable tool that not only elucidates both external and internal factors that affect the distribution of chemicals within an organism but potentially provides insight about the mechanistic linkage between environmental exposure and observed effects in the field. ${ }^{9}$

Received: September 23, 2019

Revised: December 5, 2019

Accepted: January 13, 2020

Published: January 13, 2020 
Despite the advantages of incorporating such techniques, only a few studies have organized the exposure pathway into a systematic network of time-varying concentration profiles from the contaminant source to nontarget organisms, especially in invertebrates. Ashauer et al. ${ }^{10}$ successfully predicted the risk associated with fluctuating environmental exposure to a single pesticide (diazinon) in gammarids, but their study was primarily supported by the extensive analytical measurements on which the TK (and toxicodynamic) modeling was based. In the field, data collection logistics are often a major challenge. For example, the TK parameters for individual compounds are often unavailable, and the time series of environmental concentrations required for model validation is not only analytically challenging but also costly to obtain.

In this study, we first developed strategies to overcome several model input and validation data deficiencies when applying a coupled river-TK model. We then demonstrated the applicability of this modeling framework by simulating the concentrations of 22 wastewater-derived micropollutants in nine receiving environments. The results of the river model were then employed as inputs to the TK model that predicts the internal concentrations in field invertebrates (Gammarus spp). We based our efforts on the work of Munz et al., who assessed $\sim 400$ wastewater-derived micropollutant upstream and downstream of 24 wastewater treatment plants (WWTPs) in Swiss midlands and then estimated the whole-body burden of $\sim 60$ substances in gammarids. ${ }^{11,12}$ Along with these synthesized data, we applied Monte Carlo simulations within the model to integrate the uncertainties in our input data. Furthermore, we completed additional laboratory experiments to supplement unavailable data related to TK rate constants. The simulations were first completed in 2014-2015, compared with the measured river and internal concentration data, and finally extended for long-term predictions from 2015 to 2018 . We also compared the model outputs with the results of a separate field sampling campaign conducted in May 2018. We further hypothesized that model simplifications (steady-state) may be employed for some wastewater-derived micropollutants to reduce the inputs required for predictions. We then tested these simplifications under various exposure scenarios (e.g., spills).

\section{METHODOLOGY}

2.1. Modeled Sites and General Modeling Strategy. The sites modeled in this study have been included in prior micropollutant exposure assessments upstream and downstream of representative WWTPs in Switzerland. ${ }^{11-14}$ Nine sites were selected for this study on the basis of the availability of both river and internal concentrations (sites 13, 15-19, 2123 [see Supporting Information-A]). Twenty-two wastewaterderived micropollutants were modeled among the 57 priority substances established in Munz et al. ${ }^{12}$ (Supporting Information-B, Table S3). These compounds were observed at consistently detectable in-stream concentrations during the 2014 sampling campaign, allowing for a direct comparison of simulations.

The estimates of the river concentrations were first simulated. The results were then fed into a TK model that predicts the internal concentrations in gammarids. To test model performance, the simulations were compared against previous river and internal concentration measurements ${ }^{11,12}$ (Supporting Information-C). The water samples and gammarids were from the same site (specific details found in Munz et al. ${ }^{11}$ ). Additional water samples (via passive sampling as in Moschet et al. ${ }^{15}$ ) and gammarids were collected at selected field sites in May 2018 to support the predictions (Figure S1). Sampling, sample preparation, chemical analysis, and data evaluation methodologies for this campaign were based on Munz et al. ${ }^{11} \mathrm{~A}$ brief description is also available in the Supporting Information-D.

2.2. Simulation of River Concentrations. Complete mixing conditions are typically observed in locations $\sim 70$ to $\sim 170 \mathrm{~m}$ downstream of WWTP effluents. ${ }^{14}$ This short travel distance limits the degree of mass transformation (e.g., photolysis, biodegradation) and other mass transfer mechanisms (e.g., volatilization and sorption) that occur. Hence, the following dilution model was deemed appropriate to represent the system

$$
C_{\mathrm{r}}(t)=\frac{Q_{\mathrm{w}}(t) C_{\mathrm{w}}(t)+Q_{\mathrm{u}}(t) C_{\mathrm{u}}(t)}{Q_{\mathrm{w}}(t)+Q_{\mathrm{u}}(t)}
$$

where $C_{\mathrm{r}}, C_{\mathrm{w}}$, and $C_{\mathrm{u}}(\mathrm{ng} / \mathrm{L})$ are the predicted river, wastewater effluent, and upstream concentrations that change with respect to time, $t$. $Q_{w}$ and $Q_{\mathrm{u}}\left(\mathrm{m}^{3} / \mathrm{s}\right)$ are the effluent and upstream river flows, respectively. The daily discharges at the WWTPs and upstream sites were acquired from the responsible Swiss cantonal authority (Figures S2/S3). For sites $15-17$ and 21-22, specific river flow gauges were not located immediately downstream/upstream of the WWTPs (up to $\sim 6 \mathrm{~km}$ ). When no significant stream/groundwater inputs were considered between the discharge stations and the sites, the discharge data provided by these stations were applied directly. For other sites (sites 15, 16, and 22), additional stream inputs were observed between the sites and their respective discharge stations. The area proportion method, a commonly used approach to calculate discharge in an ungauged catchment, ${ }^{16}$ was used to account for these additional flow contributions (Table S2).

We first tested the applicability of the dilution model by evaluating eq 1 with time $t$ corresponding to the sampling date in the 2014-2015 field campaign. A direct comparison of the predicted and observed river concentrations using this model (Supporting Information-E, Figure S4) suggests that this conservative simulation is suitable for predicting the downstream concentrations in small streams (Spearman correlation coefficients $(s)$ ranged from 0.87 to 0.97 ). The positive results also confirm that the area proportion method is appropriate for estimating discharge at sites with no nearby flow gauges. However, it is vital to have temporally resolved estimates of concentrations (effluent and upstream) when predicting the daily concentration fluctuations in the receiving environment. There were only six data points for each input concentration $\left(C_{\mathrm{w}}\right.$ and $C_{\mathrm{u}}$ ) from 2014 to 2015 . The use of an average sitespecific $C_{\mathrm{u}}$ as an input was justified as the measured concentration upstream did not fluctuate considerably (see Munz et al. ${ }^{12}$ ). This was not the case for effluent concentrations. Hence, we employed the MC simulation to account for the lack of temporally varying $C_{\mathrm{w}}$ data. Assuming that the six data points represent the daily fluctuations at the WWTP effluent, their mean and standard deviation defined the probability distribution function (PDF) from which the unique values were randomly sampled (10,000 times daily). The shape of the effluent concentration distribution (normal or lognormal) was based on the pooled effluent concentrations measured by a previous large-scale sampling campaign that also 

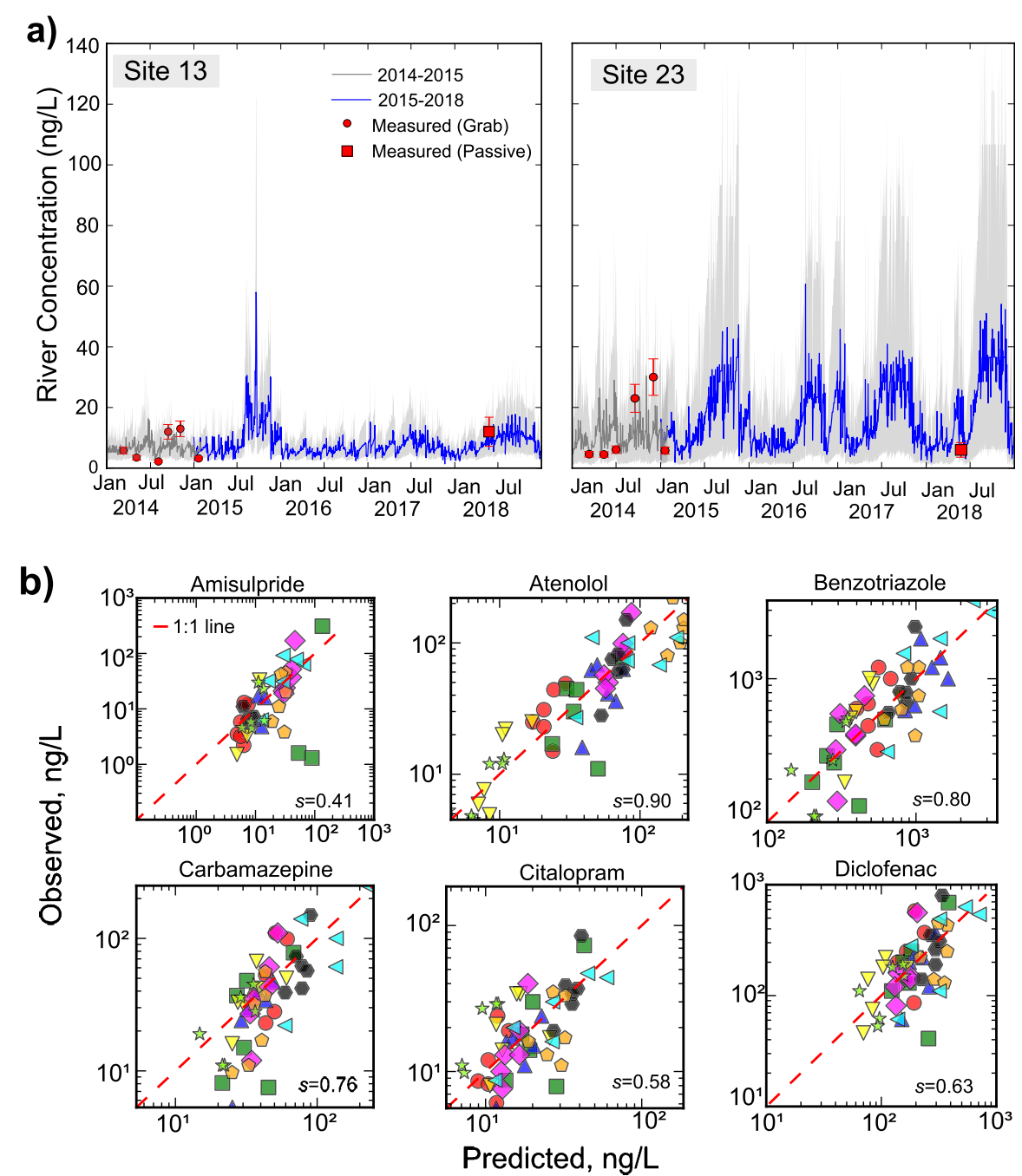

\begin{tabular}{|lllll|}
\hline Site 13 & $\nabla$ & Site 17 & & Site 21 \\
Site 15 & $\diamond$ & Site 18 & & Site 22 \\
$\boldsymbol{\Delta}$ Site 16 & $\bullet$ & Site 19 & & S Site 23 \\
\hline
\end{tabular}

Figure 1. (a) Simulations of amisulpride river concentrations downstream of WWTPs at sites 13 and 23 (2014-2018). See Figures S5/S6 for other sites and compounds. There was no replication in the 2014-2015 measured data (red circles, $\bullet$ ), but we imposed a $\pm 20 \%$ error as the measurement uncertainty; red squares $(\boldsymbol{\square})$ are time-weighted average concentrations from passive samplers deployed in May 2018. Shaded regions represent 5th and 95th percentiles in the MC simulations. (b) Comparison between predicted and measured river concentrations (log-log scale, $n$ $=54,9$ sites). Refer to Figure S5j for 16 other compounds.

includes our modeled sites (Munz et al. $^{12}$ ). The (log) normality of these data sets was tested using the ShapiroWilk test $(\alpha=0.05)$ (Table S4).

The outputs of the river model are described as distributions of daily river concentrations, which then become inputs to the TK model. The performance of the river model was determined by visually comparing the predictions with the measured river data downstream of the WWTPs. Model performance was also evaluated statistically using the Spearman correlation coefficient $(s)$ and the coefficient of determination $\left(R^{2}\right)$. All simulations and statistical evaluations were performed in SageMath 8.1, a publicly available Pythonbased mathematics software system (sample codes found in Supporting InformationSI-F).

2.3. Simulation of Internal Concentrations in Gammarids. The concentrations of target substances in gammarids were modeled using a single-compartment model (also in SageMath, Supporting InformationSI-F) expressed as

$$
\frac{\mathrm{d} C_{\mathrm{org}}}{\mathrm{d} t}=k_{\mathrm{u}} C_{\mathrm{r}}(t)-k_{\mathrm{d}} C_{\text {org }}(t)
$$

where $k_{\mathrm{u}}\left(\mathrm{L} / \mathrm{kg}_{\text {wet weight }(\mathrm{ww})} \cdot \mathrm{d}\right)$ and $k_{\mathrm{d}}(1 / \mathrm{d})$ are the uptake and depuration rate constants, respectively, $C_{\mathrm{r}}(\mathrm{ng} / \mathrm{L})$ is the river concentration (represented as a distribution of concentrations from eq 1), and $C_{\text {org }}$ is the internal concentration in gammarids $\left(\mathrm{ng} / \mathrm{g}_{\mathrm{ww}}\right.$, a multiplication factor $10^{-3}$ was applied for unit conversion). Note that only aqueous uptake (via respiration) and a lump depuration process are considered (i.e., dietary uptake and biotransformation were not included). Preexposure to our target compounds was assumed so the concentration at the beginning of the simulation $(C[t=0])$ was set to the median concentrations reported in Munz et al. ${ }^{11}$ Only 4 of the 22 target substances have reported TK rate constants for gammarids, with values varying by up to an order of magnitude (Table S12). We therefore completed additional TK experiments to determine the uptake and depuration rate 
constants that were most suitable for our field gammarids (see below).

We also observed in this TK experiment that $55 \%$ of the substances reached $95 \%$ of the steady-state concentration within the $48 \mathrm{~h}$-exposure period, with some reaching this condition in $<24 \mathrm{~h}$ (e.g., benzotriazole, climbazole, and fenofibrate) (Supporting InformationSI-G, Table S13). Hence, eq 2 a can also be represented in steady-state formulation for some compounds

$$
C_{\text {org }}(t)=\frac{k_{\mathrm{u}}}{k_{\mathrm{d}}} C_{\mathrm{r}}(t)
$$

This simplification only applies when uptake and depuration follow first-order kinetics. Under this assumption, the ratio of $k_{\mathrm{u}}$ to $k_{\mathrm{d}}$ is mathematically equivalent to the bioconcentration factor $(\mathrm{BCF}[\mathrm{L} / \mathrm{kg}])$, a parameter that is more available for gammarids than the TK rate constants. For eqs $2 a$ and $2 b$, Monte Carlo sampling of parameter values was also implemented. Specifically, $k_{\mathrm{u}}, k_{\mathrm{d}}$, and BCF were represented as a normal distribution, and the response of the model to the parameters of the MC method was also explored (Supporting InformationSI-K).

2.3.1. TK Experiments. 2.3.1.1. Collection of Gammarids. Field gammarids ( $\sim 500$ organisms) were collected via kick-net sampling on March 11, 2019, at a site where aquatic pollution was considered minimal (Grüningen, Switzerland $47^{\circ} 16^{\prime} 29.2^{\prime \prime}$ $\left.\mathrm{N}, 8^{\circ} 47^{\prime} 21.3^{\prime \prime} \mathrm{E}\right)$. Only adults were collected $(\sim 4-6 \mathrm{~mm})$; those with visible parasites and females carrying visible eggs were excluded. Leaves were also collected in situ to serve as the primary food source during the TK experiments. The animals were transported to a laboratory that was maintained at $11 \pm 2$ ${ }^{\circ} \mathrm{C}$ and a $12 \mathrm{~h} / 12 \mathrm{~h}$ light/dark cycle (Eawag, Dübendorf, Switzerland). Before any experiment, the animals were acclimatized for at least 7 days in an aquarium containing artificial pond water $\left(\mathrm{APW}^{17}\right)$ and were fed with leaves collected from the field site (pre-rinsed with nanopure water).

2.3.1.2. Uptake and Depuration Experiments. For the uptake experiment $(48 \mathrm{~h})$, the animals were randomly selected and placed in $600 \mathrm{~mL}$ transparent glass beakers (4 animals/ beaker) filled with $500 \mathrm{~mL}$ APW containing $50 \mu \mathrm{g} / \mathrm{L}$ of 61 substances in mixture (Table S13). One leaf was added to each beaker as the food source. The depuration experiment was conducted by pre-exposing the animals to the test chemical mixture for $48 \mathrm{~h}$, quickly rinsing them with nanopure water, and exposing them to $500 \mathrm{~mL}$ unspiked APW for $120 \mathrm{~h}$. The animals were sampled at seven time points during the uptake phase and 12 time points during the depuration phase, quickly rinsed with nanopure water, blotted dry with tissue, transferred into a $2 \mathrm{~mL}$ FastPrep vial which was then added with $500 \mu \mathrm{L}$ of pure methanol, and spiked with $100 \mu \mathrm{L}$ of $1000 \mu \mathrm{g} / \mathrm{L}$ internal standards (ISTD) in methanol. The vials were stored at $-20{ }^{\circ} \mathrm{C}$ until sample preparation and analysis. The exposure medium $(0.5 \mathrm{~mL})$ was also sampled at $t=0,17.5$, and $48 \mathrm{~h}$ to track any changes in nominal concentration (also spiked with $100 \mu \mathrm{L}$ of ISTD and topped with $400 \mu \mathrm{L}$ of methanol). The following experimental controls were also included: (1) gammarids and food source positive (i.e., no chemicals); (2) food source and chemical positive (i.e., no gammarids); and (3) chemical positive (i.e., no gammarids and food source). Sample preparation and analysis were similar to Fu et al. ${ }^{18}$ and are detailed in the Supporting InformationSI-G.

\section{RESULTS AND DISCUSSION}

River and gammarid concentrations were predicted while incorporating approaches that integrated (and reduced) the uncertainties associated with the input data requirements (e.g., MC sampling and laboratory experiments). Because our TK experiments revealed that some of the substances reached the steady state quickly in gammarids (within $48 \mathrm{~h}$ ), we further represented the TK model in steady-state. We discuss the general limitations of this approach below.

3.1. Simulation of River Concentrations. Satisfactory simulations were observed for all the 22 target compounds, suggesting that the $C_{\mathrm{r}}$ estimates adequately captured the river concentration (Figure 1a, Supporting InformationSI-H for all other sites), and that the MC sampling of $C_{\mathrm{w}}$ from an assumed statistical distribution is acceptable, along with the parameters used to describe its distribution (derived from the 6 observed data sets per site). Although we considered the model to produce useful river concentrations, the observed data only included "low" measurements. It would be ideal to compare the results during the periods when higher concentrations were predicted (July-December 2015, Figure 1a). However, this period corresponded to exceedingly low flow conditions, with some parts of Switzerland having experienced a record-low monthly averages ${ }^{19}$ (Figure S3). As what have been predicted here, poor dilution of wastewater effluents was likely, and higher concentrations were to be expected.

Most river concentrations fell within the boundaries of the model uncertainty (Figure S5), but there were occasions when model performance was relatively poor. For example, the model consistently underpredicted the high concentrations during the November 2015 sampling event at site 18 for most of the compounds (Figure S5e). These observations indicate that the six data points from which the PDFs were obtained did not necessarily reflect the daily fluctuations in effluent concentrations.

At present, there are no strict measures to evaluate the performance of models that predict trace organic concentrations in rivers, although Moriasi et al. ${ }^{20}$ suggested that in addition to a visual assessment, a coefficient of determination $\left(R^{2}\right.$, linear regression), that is, $>0.30$, is acceptable for fieldscale models that simulate water quality conditions (e.g., nitrogen or phosphorus). For our simulations, $R^{2}>0.30$ was mostly observed (Figures $1 \mathrm{~b}, \mathrm{~S} 5 \mathrm{j}$ for all compounds). Statistically significant correlation coefficients between measured and simulated values were also observed ( $s$ ranged from 0.41 to 0.90 ), further suggesting that the model was applicable even though it had a few limitations (Figure $1 \mathrm{~b}$ ). It is not feasible for us to identify the specific reasons for some poor predictions, but we cannot rule out the following possibilities: (1) changes in consumption patterns that were unaccounted for in the model; (2) WWTP treatment fluctuations (e.g., treatment upsets, combined sewer overflows); or (3) analytical measurement variability (e.g., changes in limits of quantification (LOQs). It is clear, however, that the model works well for most compounds that are not highly affected by the variability resulting from these factors (e.g., benzotriazole and carbamazepine).

We further recognize that the model can be refined. For instance, instead of predicting the loadings of wastewaterderived micropollutants into the aquatic environment, we could use consumption-based models wherein we would first determine the chemical usage of the population served by the 
WWTP and then estimate effluent concentrations using the compound-specific removals through the plant. Although this approach has been employed in several exposure assessment studies, ${ }^{21,22}$ the required input parameters are not only difficult to obtain (e.g., reports on usage per capita) but also highly variable. For example, reported WWTP removals can range from 0 to $81 \%$ and from 4 to $89 \%$ for diclofenac and sulfamethoxazole, respectively, ${ }^{23}$ and can be variable even within WWTPs that have similar treatment configurations. ${ }^{24}$ Hence, employing a consumption-based model for estimating effluent concentrations would likely add more uncertainties to our predictions. We have more confidence in the analytical measurements than in alternatives that employ highly uncertain input data.

To further test the applicability of the river model, we compared our predictions with an additional field sampling data point collected in May 2018 at six sites (Figures 1a; S6). Good agreement between simulated and measured stream concentrations (via passive sampling) was observed (Figure S7, $s=0.71)$. Sulfamethoxazole and hydrochlorothiazide were mostly underpredicted, but this discrepancy may be because of the passive sampling rates (Table S10) employed to calculate the time-weighted average (TWA) concentrations. Although we used the sampling rates from a similar sampler and deployed them at acceptable flow velocities, ${ }^{15}$ these values may not necessarily apply to our sites.

Despite these results, the model can still provide insight into the aquatic exposure to wastewater-derived micropollutants at our sites, especially during periods when measured data were not available. For instance, the probability that the downstream sites exceeded the EU proposed annual average environmental quality standard (AA-EQS [freshwater] $=100 \mathrm{ng} / \mathrm{L}^{25}$ ) for diclofenac is $>80 \%$ for most sites but $>95 \%$ for all sites, if the proposed Swiss chronic quality standard is used $\left(50 \mathrm{ng} / \mathrm{L}^{26}\right)$ (Figure S8). This suggests that the high exceedance is not strictly observed during a hypothetical worst-case scenario (i.e., low-flow conditions) as predicted by Ort et al. ${ }^{27}$ for Swiss river networks. Instead, there may also be a high risk of wastewaterderived micropollutant exposure both during normal flow conditions as illustrated by our model predictions. In some cases, the exceedances could last $\sim 10$ months as in site 13 or $\sim 2$ years, if the Swiss chronic water quality standard was considered (Figure S6a). Whether these exceedances necessitate further management action requires additional investigation, especially on the long-term ecotoxicological effects of this substance. However, many WWTPs in Switzerland are implementing (or have implemented) advanced treatment upgrades such as ozonation and/or activated carbon, and diclofenac is eliminated well by both technologies. ${ }^{28,29}$ It may be useful to revisit this model to assess the improvements. Nevertheless, we have produced river concentration simulations that are considered to be sufficient input values for the internal concentration simulations.

3.2. Modeling the Internal Concentrations in Gammarids. 3.2.1. Lab Determination of Uptake and Depuration Rate Constants. We completed an additional lab experiment to address the lack of data on rate constants required for the TK model. We could calculate the experimental values for 42 substances of the 61 chemicals in the mixture (Figure 2a). Of the 19 compounds with indeterminable rate constants, we observed 14 compounds that showed poor analytical method performance (e.g., high background noise, poor calibration curve, and methylation in a)

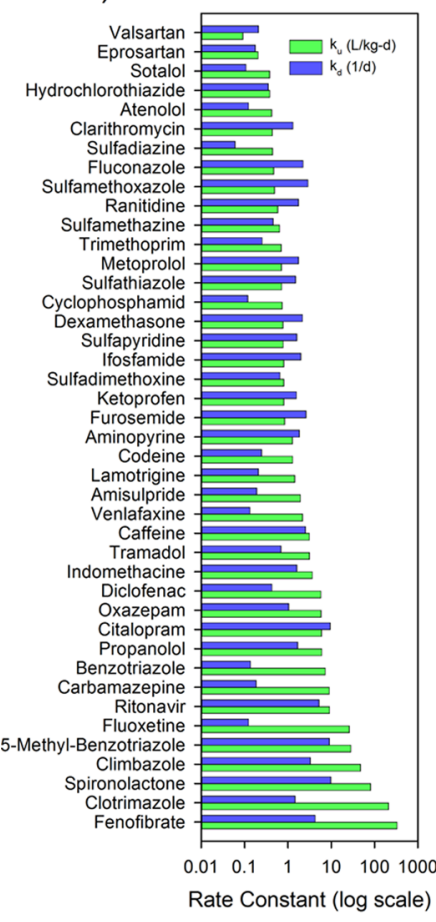

b)

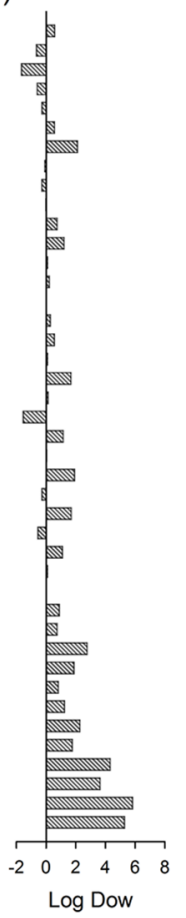

c)

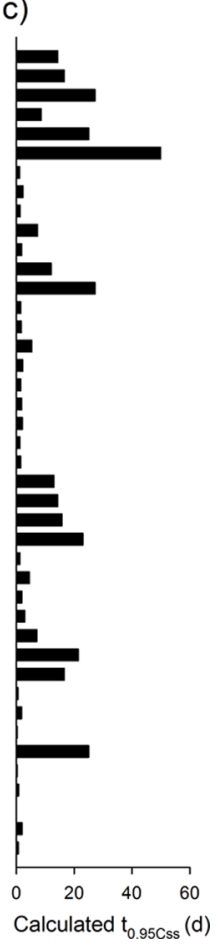

Figure 2. (a) Uptake $\left(k_{\mathrm{u}}\right)$ and depuration $\left(k_{\mathrm{d}}\right)$ rate constants of 41 wastewater-derived micropollutants obtained from the laboratory experiment shown with increasing $k_{\mathrm{u}}$; (b) their corresponding log Dow (adjusted to $\mathrm{pH} 7.9$ ); and (c) their TK characteristics in gammarids described by the time for the internal concentration to reach $95 \%$ of the steady-state concentration $\left(t_{0.95 \mathrm{Css}}\right)$. Most of the compounds have $t_{0.95 \mathrm{Css}}<24-48 \mathrm{~h}(55 \%)$. See Table S13 for the numerical values.

standard), and five were not detected in gammarids above the LOQ (Table S13).

Evaluating the exact mechanism of uptake and depuration of these chemicals in gammarids was not the goal of this study, but useful patterns of uptake and depuration rate constants can be determined from the experiments. For instance, when we evaluated the BCFs (Table S13), we found them to be substantially lower than the REACH criterion for bioaccumulation $(2000 \mathrm{~L} / \mathrm{kg})$, suggesting that these substances are not highly bioaccumulative in gammarids. Although there are other properties that influence the chemical uptake (e.g., organism weight, ventilation rate), ${ }^{30,31}$ bioaccumulation is highly linked to hydrophobicity. ${ }^{32}$ The lab-derived rate constants reflect this relationship as these compounds with relatively high uptake rate constants $(>10 \mathrm{~L} / \mathrm{kg} \cdot \mathrm{d})$ tend to have higher log Dow values (log Dow is the $\mathrm{pH}$-corrected octanol-water partitioning coefficient) (Figure $2 \mathrm{~b}$, Table S13). We further found that the $55 \%$ of the compounds reached $95 \%$ of the steady-state concentration $\left(t_{0.95 \mathrm{Css}}\right)$ in $<24-48 \mathrm{~h}$ (Figure $2 \mathrm{c}$, Table S13), suggesting that most of the compounds in gammarids equilibrate relatively quickly with the external concentration.

Our ability to compare these results with literature values was limited because only a few studies on TK experiments specific to gammarids exist (Table S12). The TK rate constants we obtained for carbamazepine $(6.1 \mathrm{~L} / \mathrm{kg}-\mathrm{d}, 1.7 \mathrm{1} /$ d) were similar to those of Meredith-Williams et al. ${ }^{33}(5.2 \mathrm{~L} /$ $\mathrm{kg} \cdot \mathrm{d} \& 0.7 \mathrm{1} / \mathrm{d}$ ) but an order of magnitude higher than those reported by Miller et $\mathrm{al}^{34}(0.53 \mathrm{~L} / \mathrm{kg} \cdot \mathrm{d} \& 0.02 \mathrm{1} / \mathrm{d})$. To integrate the uncertainties associated with the rate constants, 
a)
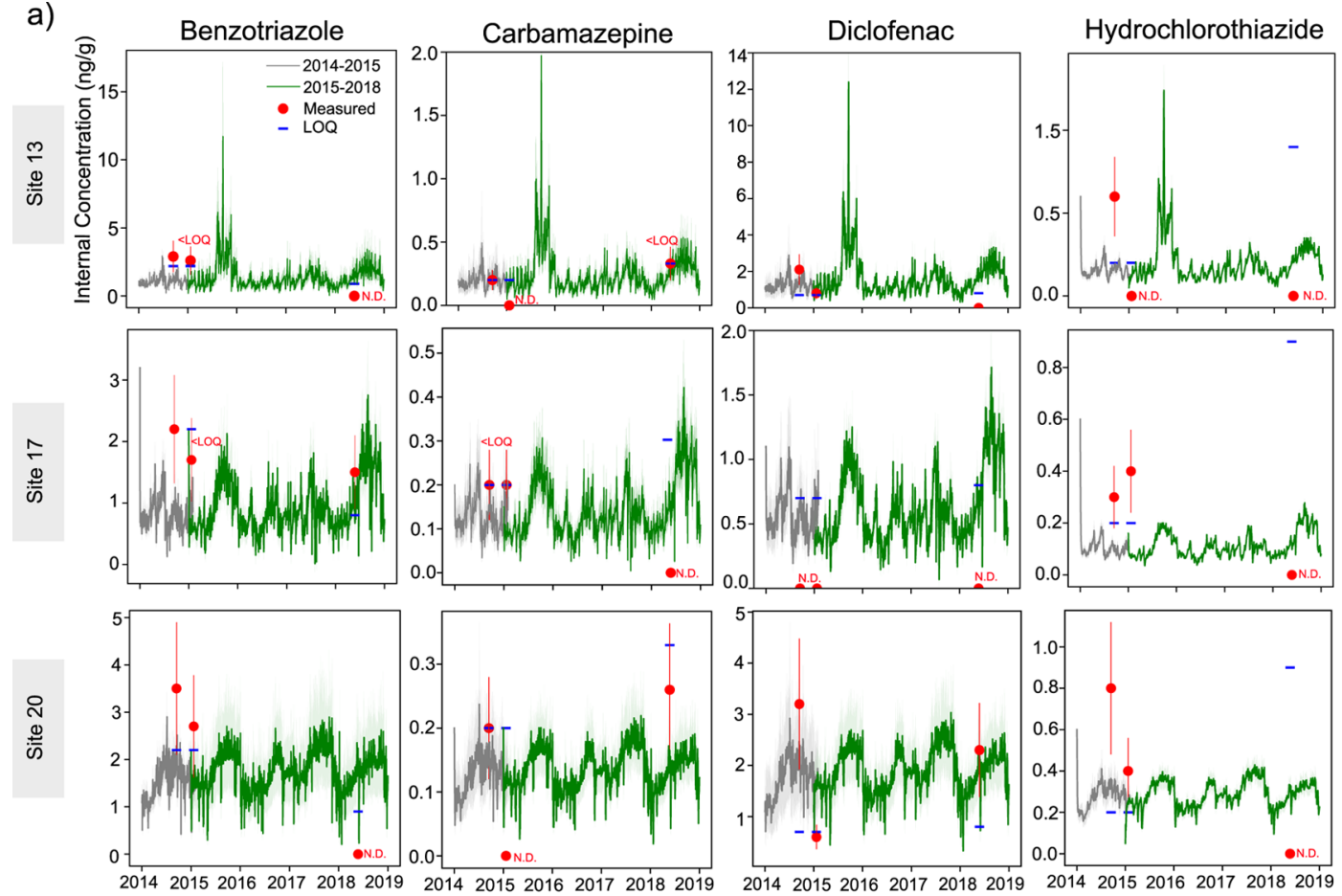

b)
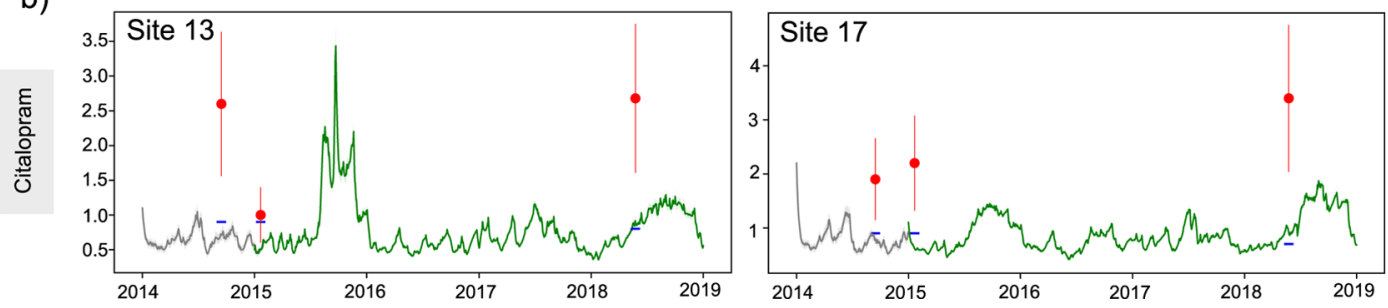

Figure 3. (a) Simulated internal concentrations in gammarids (2014-2018) compared with the measured data ( $\pm 40 \%$ error) (Figure S9 for other sites). The input river concentrations were derived from the dilution model. N.D. = not detected. LOQ = limit of quantification. (b) Citalopram concentrations were mostly underpredicted. Each measured data required an average $\sim 30-50$ gammarids to achieve a sample of $\sim 500 \mathrm{mg}$ required for chemical analysis.

we incorporated another MC sampling of $k_{\mathrm{u}}$ and $k_{\mathrm{d}}$ within the model (eq $2 \mathrm{a}$ ), assuming that these parameters are normally distributed (Supporting InformationSI-K).

3.3. Internal Concentration Simulation. Of the 22 compounds simulated using the river dilution model, carbamazepine, citalopram, benzotriazole, diclofenac, and hydrochlorothiazide were selected for internal concentration simulation because of their high frequency of detection in field gammarids at our study sites (which also supports better model comparison). Overall, good agreement between the measured and simulated data was observed (Figure 3), with the predictions only differing by a factor of $0.1-1.9$ (Table S15). Although some discrepancies existed between the measured and observed data, they primarily occurred when the concentrations were close to the LOQs (Tables S5/S6) or simply not detected (e.g., hydrochlorothiazide in Figure 3). This observation reinforces the usefulness of models when chemical measurements are limited to issues related to detection limits. To further test the model and the assumptions within our framework, additional measured values at various time points during the 5 year simulation would have been valuable (only 3 observations were available per site). However, satisfactory predictions of internal concentrations were observed when the same assumptions were subsequently applied to all other sites (Figure S9).

Assuming that the whole-body concentrations in gammarids are mostly attributed to aqueous-phase exposure (i.e., minimal dietary and/or sediment exposures), the simulations suggest that the internal concentrations quickly respond to the stream concentration fluctuations. This observation is particularly reflected by the similarities between the river dilution and internal concentration patterns at each site (Figures S6 and S9), indicating that whenever peak concentrations are detected in the stream, peaks in internal concentrations are probably going to be experienced as well. As expected, low-flow conditions were associated with high internal concentrations in gammarids and these patterns were not only observed during the summer months (June-August). It may be of interest to examine the changes in organism responses relative to the exposures, especially when the peak internal concentrations coincide with the critical period in gammarid development (e.g., growth and reproduction). Because most wastewater-derived micropollutant inputs into the receiving environments are fairly consistent relative to pesticide pulses during storm events, the daily river dilution patterns can be employed as a preliminary estimate of peak exposures. 

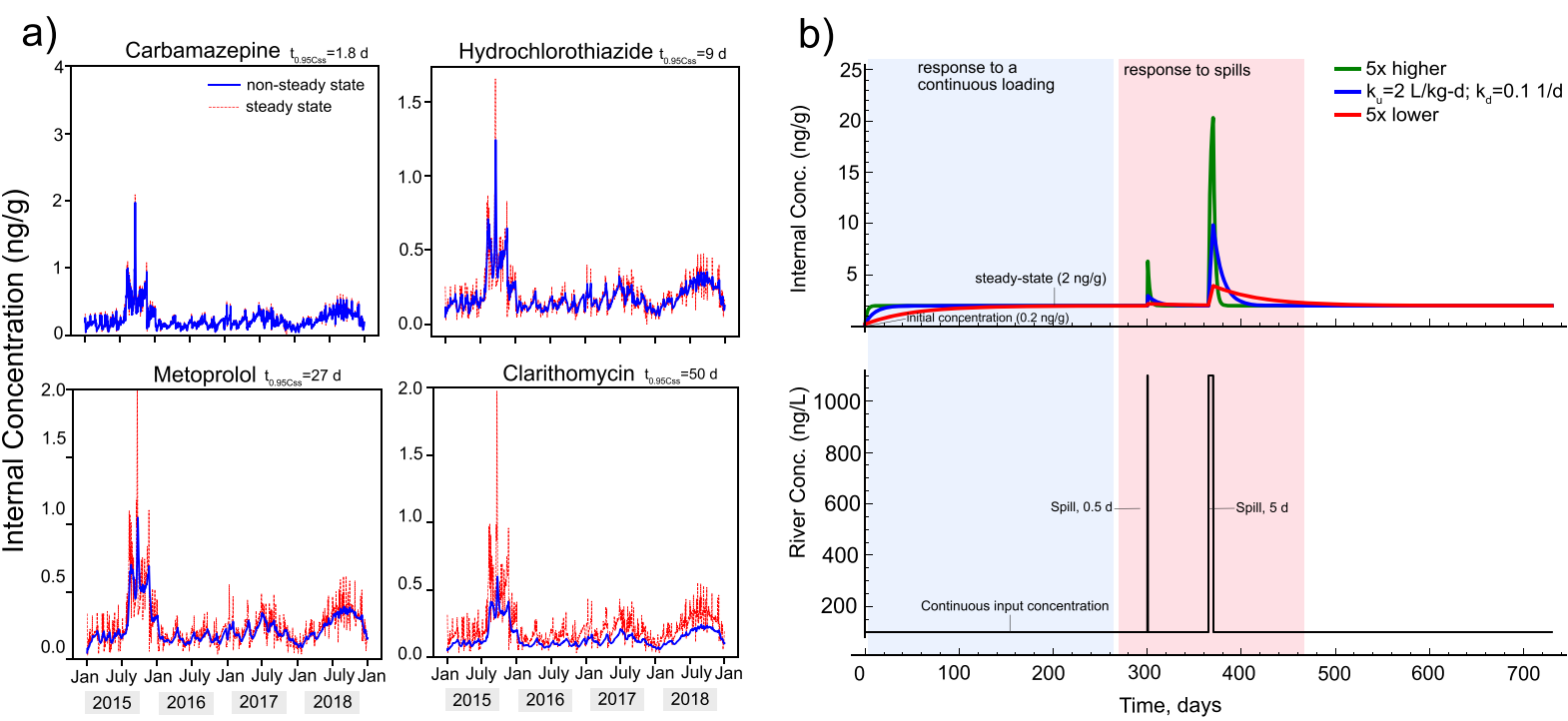

Figure 4. (a) Steady-state vs nonsteady-state internal concentration simulations for compounds with different TK characteristics in gammarids. Steady-state simulations may be assumed for compounds with fast uptake/depuration such as carbamazepine $\left(t_{0.95 C s s}\right.$ of $\left.<48 \mathrm{~h}\right)$. This simulation may also be used for compounds with $t_{0.95 \mathrm{Css}}>48 \mathrm{~h}$ (hydrochlorothiazide, metoprolol, and clarithromycin), but the predictions will be overestimated during peak exposure (hence, provide conservative estimates). (b) Additional exposure scenarios and different TK rate constant combinations were tested under a hypothetical nonsteady-state simulation. The blue region describes the response to a continuous input concentration $(100 \mathrm{ng} / \mathrm{L})$, which asymptotically converges at the steady state $(2 \mathrm{ng} / \mathrm{g})$. The time to reach the steady state changes depending on the magnitude of rate constants. The red region illustrates the responses to spills (at $1000 \mathrm{ng} / \mathrm{L}$ ) occurring at different durations (at $t=300 \mathrm{~d}$ for $0.5 \mathrm{~d}$ and $t=365 \mathrm{~d}$ for $5 \mathrm{~d}$ ). The response to pulse inputs varies depending on the spill duration, and finally, the peak exposure and recovery period after the spill are driven by the magnitude of rate constants.

Overall, the coupled river-TK model adequately predicted the whole-body burden of selected wastewater-derived micropollutants in gammarids, and the temporally varying internal concentrations predicted by the coupled model can be used in the future to formulate hypotheses on the likelihood and degree of toxicological effects associated with exposure.

3.3.1. Poor TK Model Predictions-the Case of Citalopram. The internal concentrations were found to be predicted well for carbamazepine, benzotriazole, diclofenac, and hydrochlorothiazide but not for citalopram (Figure 3b). The model underestimated the citalopram concentrations in gammarids by up to 4-5 times. To eliminate the possibility that the poor prediction may have been because of our model assumptions, we tested the response of the model by conducting a sensitivity analysis on the parameters of the MC method (Supporting InformationSI-K). It was observed that increasing the standard deviation of the assumed normal distribution increased the uncertainty region, but the predictions still remained outside of this region (Supporting InformationSI-K).

Because citalopram is one of the compounds that did not reach the steady state fast enough ( $>21$ days based on our TK experiments), we cannot rule out the uptake of citalopram via other pathways that were not considered in the model and in the laboratory exposure study. In many streams, biofilms colonize the leaf surfaces rapidly and enhances the palatability of the leaves to detritus feeders such as gammarids. ${ }^{35}$ There are evidences suggesting that micropollutants can sorb onto biofilms, ${ }^{36,37}$ potentially adding another uptake route when consumed by gammarids. Furthermore, gammarids are found in benthic habitats characterized by a high degree of contact with the sediments, a layer that provides a "sink" for organic compounds especially when they are moderately to highly sorptive. Citalopram has been reported in surface sediments and biofilms in effluent-receiving environments world- wide. $^{38-40}$ Unfortunately, we do not have any data at our sites to address these possibilities, but field investigation is underway to determine if such a pattern occurs.

3.3.2. Steady-State Simulation of Internal Concentration. We further hypothesized that fast equilibrium between water and internal concentrations may be assumed for most compounds (eq $2 \mathrm{~b}$ ). This assumption is supported by our laboratory study that suggests the relatively fast uptake and depuration of most wastewater-derived micropollutants in gammarids (recall that $55 \%$ of the compounds in our experiment reached $95 \%$ of the steady-state concentration $\left[t_{0.95 \mathrm{Css}}\right]$ in $<48 \mathrm{~h}$, Figure 2$)$. Under this simulation, the internal concentrations can be simply estimated by a scaling factor that relates the temporally varying river concentration to the internal concentrations. This scaling factor is exactly represented by the BCF as described in the steady-state version of the TK model (eq $2 b$ ).

We tested this hypothesis for carbamazepine that was observed to reach $95 \%$ of the steady-state concentration after $1.8 \mathrm{~d}$ (Table S13). Similar to $k_{\mathrm{u}}$ and $k_{\mathrm{d}}$, we represented the BCFs as normally distributed and then sampled this parameter using MC. We found no substantial difference between steadystate and nonsteady-state simulations (Figure 4a). Hence, the proposed simplification is acceptable for this compound and quite possibly for those that have reached the steady state in $<48 \mathrm{~h}$. The same hypothesis was applied to compounds that took longer to reach the steady state as they have slower uptake and depuration rate constants (Figure 4a). Clarithromycin and metoprolol, in particular, reach $95 \%$ of steady-state concentration after 50 days and 27 days, respectively (Table S13). Here, both simulations followed the same concentration patterns, although the steady-state predictions showed rapid changes in concentrations compared to a "smoother" concentration curve by nonsteady-state simulations. 
Although the steady-state simulation tended to overestimate the concentrations during peak exposures, it could be employed to derive conservative estimates of internal concentrations. For instance, when the upstream contaminant contribution is minimal, a simpler coupled river-TK model that only requires the effluent concentration $\left(C_{\mathrm{w}}(t)\right)$, dilution factor (DF), and BCFs may be employed (eq 3)

$$
C_{\text {org }}(t)=\mathrm{BCF} \times \frac{1}{\mathrm{DF}} C_{\mathrm{w}}(t)
$$

where DF is the ratio between the total river discharge and WWTP effluent discharge. This approach can prove beneficial, especially when a rapid estimate of internal concentrations of wastewater-derived chemicals in exposed aquatic organisms is desired.

Note that steady-state assumptions do not take the magnitudes of rate constants into account, and there will be situations when nonsteady-state simulations are more appropriate (hence the absolute values of rate constants matter). Supposed we test the response of gammarids at different exposure conditions for a compound with a BCF of $20 \mathrm{~L} / \mathrm{kg}$. This is a fair assumption, considering that the micropollutants we examined in our experiments have BCFs ranging from 0.2 to $200 \mathrm{~L} / \mathrm{kg}$ (Table S13). From here, we assumed a baseline $k_{\mathrm{u}}$ of $2 \mathrm{~L} / \mathrm{kg} \cdot \mathrm{d}$ and $k_{\mathrm{d}}$ of $0.1 \mathrm{1} / \mathrm{d}$. Then, we varied the magnitude of these rate constants by five times higher or lower but their ratios are mathematically the same for all scenarios. We further assumed that the gammarids have an initial internal concentration of $0.2 \mathrm{ng} / \mathrm{g}$, which is in the range of the median values of internal concentrations reported by Munz et al. ${ }^{11}$

We then examined the individual responses in internal concentrations at different contaminant input conditions (Figure $4 b$, lower graph). First, we introduced a constant and continuous river concentration of $100 \mathrm{ng} / \mathrm{L}$ as exposure for gammarids. Here, the system converges to the steady state ( $2 \mathrm{ng} / \mathrm{g}$ ), but the time to reach this condition was achieved at different periods, depending on the rate constant combinations employed (Figure 4b, blue-shaded region). Then, we tested the hypothetical response of gammarids during spills occurring for 0.5 and $5 \mathrm{~d}$ in addition to the continuous input concentrations they experience (spill has a magnitude of $1000 \mathrm{ng} / \mathrm{L}$ ). If one assumes a relatively fast equilibrium, the internal concentration is equivalent to the exposure concentration multiplied by the BCF (BCF is simply $k_{\mathrm{u}} / k_{\mathrm{d}}$ assuming first-order). Hence, if the gammarids equilibrate quickly with the river concentration, then the internal concentration will be $22 \mathrm{ng} / \mathrm{g}$ for the entire spill duration $\left(C_{\exp }=1100 \mathrm{ng} / \mathrm{L}, \mathrm{BCF}=\right.$ $20 \mathrm{~L} / \mathrm{kg}$ ). However, this exercise shows that if the duration of the spill is short $(<0.5 \mathrm{~d})$, the gammarids will never reach this concentration (Figure $4 \mathrm{~b}$, red region). Therefore, the peak internal concentration will be highly overestimated if a fast equilibrium at short-duration spills is assumed. For longer duration spills, where the gammarids are given enough time to respond to a perturbation, the peak concentrations are higher and approach the equilibrium concentration, especially when larger rate constants are employed.

Regardless of the scenarios, the fast equilibrium assumption always produces conservative estimates of peak concentration. However, if one wants to determine a more precise exposure scenario where the exact magnitude of peak exposures and the recovery periods are of interest, then a nonsteady-state formulation should be employed. This representation must also be supported by compound-specific uptake and depuration rate constants either via laboratory experiments or from reliable sources, as the magnitude of rate constants can clearly have an impact on the predictions during the nonsteady-state period.

\section{ENVIRONMENTAL IMPLICATIONS AND STUDY LIMITATIONS}

Our coupled river-TK model is a simple approach that provided an informed estimate of the environmental concentrations of select wastewater-derived micropollutants in the receiving environment and whole-body burden in a nontarget organism. We further addressed the uncertain and insufficient input data using statistical (MC sampling) and experimental (TK rate constants) methods. However, we recognize that the measured data in the model validation stage may not be sufficient to permit the application of this model to a full spectrum of environmental conditions. It is in our intention to employ this model as a supplement to existing field measurements (not as a substitute), especially in datapoor areas. On the account that this modeling work was a preliminary attempt to coherently describe micropollutant exposure from the source (WWTP) to nontarget organisms, we have obtained satisfactory results that demonstrate the utility of coupled river-TK model to assess exposure better.

A key and practical finding here is the assumption of fast equilibrium when predicting the temporal dynamics such that scaling factors (daily DFs and BCFs) can be employed to estimate the river and internal concentrations in gammarids, provided that the concentrations at the source are specified, and the compounds quickly equilibrate in gammarids (i.e., $t_{0.95 \mathrm{Css}}<48 \mathrm{~h}$ ). This approach decreased the amount of required input data, which are often unavailable or difficult to obtain. Obviously, there are limitations as to when the steady state can be employed (e.g., highly overestimates peak concentrations in short-duration spills), but the proposed simplification (eq 3) can provide a "rule-of-thumb" approach that may be useful in practical applications especially during the initial stages of exposure assessments.

Our current regulatory paradigm employs environmental concentrations as surrogate indicators of risk. However, environmental concentrations do not include the bioavailable fractions, multiple routes of contaminant uptake in organisms, and the impact of toxicant biotransformation. Hence, solely examining the external concentrations (i.e., river concentrations) allows a limited view of the true risk. This is exactly illustrated by the recent finding of Shahid et al. ${ }^{41}$ who suggested that the overall exposure to pesticides is explained better when employing internal concentrations instead of river concentrations. Furthermore, this work fully supports the recommendations of many studies ${ }^{5,42}$ that reiterate the integration of internal concentration patterns as a critical first step in linking exposure to effects.

The simulated internal concentrations may be coupled further with effects modeling to provide insight into the impacts of wastewater-derived micropollutants at different levels of biological organization. For instance, it would be of interest to incorporate other life-cycle processes (migration, life span, clutch size, and postreproductive survival) to assess the impact of micropollutant exposure in field gammarid population. In the future, it is also important to consider the applicability of this modeling framework to pesticides because these compounds have been previously found to contribute 
substantially to the overall risk of micropollutant exposure in streams. $^{11}$

\section{ASSOCIATED CONTENT}

\section{SI Supporting Information}

The Supporting Information is available free of charge at https://pubs.acs.org/doi/10.1021/acs.est.9b05736.

Site description of the modeled sites; properties of the 22 modeled substances; summary of measured data (2014-2015); sampling protocol, analytical methods, and the results of the May 2018 sampling campaign; dilution model preliminary predictions; SageMath/ Python codes; tabulated lab-derived TK rate constants; river model performance; internal concentration simulations; and model response to different Monte Carlo assumptions (PDF)

\section{AUTHOR INFORMATION}

\section{Corresponding Authors}

Maricor J. Arlos - Eawag, Swiss Federal Institute of Aquatic Science and Technology, 8600 Dübendorf, Switzerland; Institute of Biogeochemistry and Pollutant Dynamics, ETH Zürich, 8092 Zürich, Switzerland; 이이.org/0000-0001-6365-3955; Email: maricor.arlos@eawag.ch

Juliane Hollender - Eawag, Swiss Federal Institute of Aquatic Science and Technology, 8600 Dübendorf, Switzerland; Institute of Biogeochemistry and Pollutant Dynamics, ETH Zürich, 8092 Zürich, Switzerland; 이이.orid.o000-0002-4660-274X; Email: juliane.hollender@eawag.ch

\section{Authors}

Florian Schürz - Institute of Biogeochemistry and Pollutant Dynamics, ETH Zürich, 8092 Zürich, Switzerland

Qiuguo Fu - Eawag, Swiss Federal Institute of Aquatic Science and Technology, 8600 Dübendorf, Switzerland; $\odot$ orcid.org/ 0000-0002-4227-5948

Benedikt B. Lauper - Eawag, Swiss Federal Institute of Aquatic Science and Technology, 8600 Dübendorf, Switzerland; Institute of Biogeochemistry and Pollutant Dynamics, ETH Zürich, 8092 Zürich, Switzerland

Christian Stamm - Eawag, Swiss Federal Institute of Aquatic Science and Technology, 8600 Dübendorf, Switzerland

Complete contact information is available at:

https://pubs.acs.org/10.1021/acs.est.9b05736

\section{Notes}

The authors declare no competing financial interest.

\section{ACKNOWLEDGMENTS}

This study received funding from the ETH-Zurich Postdoctoral Fellowships (0-20400-17, co-funded by the European Union's Seventh Framework Programme for Research and Technological Development under grant agreement 608881, 2015-2019). We acknowledge financial support of the Natural Sciences and Engineering Research Council of Canada (PDF517151-2018) and the Swiss National Science Foundation (200020_184878). We thank Marta Reyes, Christelle Oltramare, Nicolas Creusot, Birgit Beck from Eawag, and Mark Servos from the University of Waterloo for their help with the field sampling. Finally, we acknowledge the assistance of Julita Stadnicka and Andreas Scheidegger (Eawag) with our modeling strategy.

\section{REFERENCES}

(1) Corcoran, J.; Winter, M. J.; Tyler, C. R. Pharmaceuticals in the aquatic environment: a critical review of the evidence for health effects in fish. Crit. Rev. Toxicol. 2010, 40, 287-304.

(2) Arnold, K. E.; Brown, A. R.; Ankley, G. T.; Sumpter, J. P. Medicating the environment: assessing risks of pharmaceuticals to wildlife and ecosystems. Philos. Trans. R. Soc., B 2014, 369, 20130569.

(3) Schwarzenbach, R. P.; Escher, B. I.; Fenner, K.; Hofstetter, T. B.; Johnson, C. A.; Von Gunten, U.; Wehrli, B. The challenge of micropollutants in aquatic systems. Science 2006, 313, 1072-1077.

(4) EUDecision. Commission Implementing Decision (EU) 2018/ 840 of 5 March 2018 establishing a watch list of substances for Unionwide monitoring in the field of water policy pursuant to Directive 2008/105/EC of the European Parliament and of the Council. Off. J. Eur. Union L 2018, 141, 9-11.

(5) Teeguarden, J. G.; Tan, Y.-M.; Edwards, S. W.; Leonard, J. A.; Anderson, K. A.; Corley, R. A.; Kile, M. L.; Simonich, S. M.; Stone, D.; Tanguay, R. L.; Waters, K. M.; Harper, S. L.; Williams, D. E. Completing the link between exposure science and toxicology for improved environmental health decision making: The aggregate exposure pathway framework. Environ. Sci. Technol. 2016, 50, 45794586.

(6) Landrum, P. F.; Lydy, M. J.; Lee, H., II. Toxicokinetics in aquatic systems: Model comparisons and use in hazard assessment. Environ. Toxicol. Chem. 1992, 11, 1709-1725.

(7) Roig, B.; D'Aco, V. Distribution of Pharmaceutical Residues in the Environment; The Royal Society of Chemistry, 2016; pp 34-69.

(8) Jager, T. Predicting environmental risk: A road map for the future. J. Toxicol. Environ. Health, Part A 2016, 79, 572-584.

(9) Ashauer, R.; Escher, B. I. Advantages of toxicokinetic and toxicodynamic modelling in aquatic ecotoxicology and risk assessment. J. Environ. Monit. 2010, 12, 2056-2061.

(10) Ashauer, R.; Wittmer, I.; Stamm, C.; Escher, B. I. Environmental risk assessment of fluctuating diazinon concentrations in an urban and agricultural catchment using toxicokinetic-toxicodynamic modeling. Environ. Sci. Technol. 2011, 45, 9783-9792.

(11) Munz, N. A.; Fu, Q.; Stamm, C.; Hollender, J. Internal Concentrations in Gammarids Reveal Increased Risk of Organic Micropollutants in Wastewater-Impacted Streams. Environ. Sci. Technol. 2018, 52, 10347-10358.

(12) Munz, N. A.; Burdon, F. J.; De Zwart, D.; Junghans, M.; Melo, L.; Reyes, M.; Schönenberger, U.; Singer, H. P.; Spycher, B.; Hollender, J.; Stamm, C. Pesticides drive risk of micropollutants in wastewater-impacted streams during low flow conditions. Water Res. 2017, 110, 366-377.

(13) Neale, P. A.; Munz, N. A.; Aït-Aïssa, S.; Altenburger, R.; Brion, F.; Busch, W.; Escher, B. I.; Hilscherová, K.; Kienle, C.; Novák, J.; Seiler, T.-B.; Shao, Y.; Stamm, C.; Hollender, J. Integrating chemical analysis and bioanalysis to evaluate the contribution of wastewater effluent on the micropollutant burden in small streams. Sci. Total Environ. 2017, 576, 785-795.

(14) Stamm, C.; Räsänen, K.; Burdon, F. J.; Altermatt, F.; Jokela, J.; Joss, A.; Ackermann, M.; Eggen, R. I. L., Chapter Four - Unravelling the Impacts of Micropollutants in Aquatic Ecosystems: Interdisciplinary Studies at the Interface of Large-Scale Ecology. In Advances in Ecological Research; Dumbrell, A. J., Kordas, R. L., Woodward, G., Eds.; Academic Press, 2016; Vol. 55, pp 183-223.

(15) Moschet, C.; Vermeirssen, E. L. M.; Singer, H.; Stamm, C.; Hollender, J. Evaluation of in-situ calibration of Chemcatcher passive samplers for 322 micropollutants in agricultural and urban affected rivers. Water Res. 2015, 71, 306-317.

(16) Gianfagna, C. C.; Johnson, C. E.; Chandler, D. G.; Hofmann, C. Watershed area ratio accurately predicts daily streamflow in nested catchments in the Catskills, New York. J. Hydrol. Reg. Stud. 2015, 4, 583-594.

(17) Rösch, A.; Anliker, S.; Hollender, J. How Biotransformation Influences Toxicokinetics of Azole Fungicides in the Aquatic Invertebrate Gammarus pulex. Environ. Sci. Technol. 2016, 50, $7175-7188$. 
(18) Fu, Q.; Rösch, A.; Fedrizzi, D.; Vignet, C.; Hollender, J. Bioaccumulation, Biotransformation, and Synergistic Effects of Binary Fungicide Mixtures in Hyalella azteca and Gammarus pulex: How Different/Similar are the Two Species? Environ. Sci. Technol. 2018, 52, 13491-13500.

(19) Federal Office of the Environment. Hydrological yearbook of Switzerland 2015; Federal Office of the Environment: Switzerland, Bern, 2016; p 36.

(20) Moriasi, D. N.; Gitau, M. W.; Pai, N.; Daggupati, P. Hydrologic and water quality models: Performance measures and evaluation criteria. Trans. ASABE 2015, 58, 1763-1785.

(21) ter Laak, T. L.; Kooij, P. J. F.; Tolkamp, H.; Hofman, J. Different compositions of pharmaceuticals in Dutch and Belgian rivers explained by consumption patterns and treatment efficiency. Environ. Sci. Pollut. Res. 2014, 21, 12843-12855.

(22) Johnson, A. C.; Williams, R. J. A model to estimate influent and effluent concentrations of estradiol, estrone, and ethinylestradiol at sewage treatment works. Environ. Sci. Technol. 2004, 38, 3649-3658.

(23) Luo, Y.; Guo, W.; Ngo, H. H.; Nghiem, L. D.; Hai, F. I.; Zhang, J.; Liang, S.; Wang, X. C. A review on the occurrence of micropollutants in the aquatic environment and their fate and removal during wastewater treatment. Sci. Total Environ. 2014, 473474, 619-641.

(24) Jelić, A.; Gros, M.; Petrović, M.; Ginebreda, A.; Barceló, D., Occurrence and Elimination of Pharmaceuticals During Conventional Wastewater Treatment. In Emerging and Priority Pollutants in Rivers: Bringing Science into River Management Plans; Guasch, H., Ginebreda, A., Geiszinger, A., Eds.; Springer Berlin Heidelberg: Berlin, Heidelberg, 2012; pp 1-23.

(25) European Commission. Proposal for a Directive of the European Parliament and of the Council Amending Directives 2000/60/EC and 2008/105/EC as Regards Priority Substances in the Field of Water Policy; SWD(2012) 379; European Commision: Brussels, November 14, 2012.

(26) Ecotox Centre. https://www.ecotoxcentre.ch/expert-service/ quality-standards/proposals-for-acute-and-chronic-quality-standards/ (accessed August 21, 2019).

(27) Ort, C.; Hollender, J.; Schaerer, M.; Siegrist, H. Model-Based Evaluation of Reduction Strategies for Micropollutants from Wastewater Treatment Plants in Complex River Networks. Environ. Sci. Technol. 2009, 43, 3214-3220.

(28) Hollender, J.; Zimmermann, S. G.; Koepke, S.; Krauss, M.; McArdell, C. S.; Ort, C.; Singer, H.; von Gunten, U.; Siegrist, H. Elimination of Organic Micropollutants in a Municipal Wastewater Treatment Plant Upgraded with a Full-Scale Post-Ozonation Followed by Sand Filtration. Environ. Sci. Technol. 2009, 43, 78627869.

(29) Boehler, M.; Zwickenpflug, B.; Hollender, J.; Ternes, T.; Joss, A.; Siegrist, H. Removal of micropollutants in municipal wastewater treatment plants by powder-activated carbon. Water Sci. Technol. 2012, 66, 2115-2121.

(30) Landrum, P. F. Toxicokinetics of organic xenobiotics in the amphipod, Pontoporeia hoyi: role of physiological and environmental variables. Aquat. Toxicol. 1988, 12, 245-271.

(31) Larisch, W.; Goss, K.-U. Uptake, distribution and elimination of chemicals in fish-Which physiological parameters are the most relevant for toxicokinetics? Chemosphere 2018, 210, 1108-1114.

(32) Sijm, D. T.; Rikken, M.; Rorije, E.; Traas, T.; McLachlan, M.; Peijnenburg, W., Transport, accumulation and transformation processes. In Risk Assessment of Chemicals; Springer, 2007; pp 73158.

(33) Meredith-Williams, M.; Carter, L. J.; Fussell, R.; Raffaelli, D.; Ashauer, R.; Boxall, A. B. A. Uptake and depuration of pharmaceuticals in aquatic invertebrates. Environ. Pollut. 2012, 165, 250-258.

(34) Miller, T. H.; McEneff, G. L.; Stott, L. C.; Owen, S. F.; Bury, N. R.; Barron, L. P. Assessing the reliability of uptake and elimination kinetics modelling approaches for estimating bioconcentration factors in the freshwater invertebrate, Gammarus pulex. Sci. Total Environ. 2016, 547, 396-404.

(35) Kreutzweiser, D. P.; Capell, S. S. Palatability of leaf material contaminated with Bacillus thuringiensis var. kurstaki, to Hydatophylax argus, a detritivorous aquatic insect. Bull. Environ. Contam. Toxicol. 1996, 56, 80-84.

(36) Torresi, E.; Polesel, F.; Bester, K.; Christensson, M.; Smets, B. F.; Trapp, S.; Andersen, H. R.; Plósz, B. G. Diffusion and sorption of organic micropollutants in biofilms with varying thicknesses. Water Res. 2017, 123, 388-400.

(37) Writer, J. H.; Ryan, J. N.; Barber, L. B. Role of Biofilms in Sorptive Removal of Steroidal Hormones and 4-Nonylphenol Compounds from Streams. Environ. Sci. Technol. 2011, 45, 72757283.

(38) Schultz, M. M.; Furlong, E. T.; Kolpin, D. W.; Werner, S. L.; Schoenfuss, H. L.; Barber, L. B.; Blazer, V. S.; Norris, D. O.; Vajda, A. M. Antidepressant Pharmaceuticals in Two U.S. Effluent-Impacted Streams: Occurrence and Fate in Water and Sediment, and Selective Uptake in Fish Neural Tissue. Environ. Sci. Technol. 2010, 44, 19181925.

(39) Koba, O.; Grabicova, K.; Cerveny, D.; Turek, J.; Kolarova, J.; Randak, T.; Zlabek, V.; Grabic, R. Transport of pharmaceuticals and their metabolites between water and sediments as a further potential exposure for aquatic organisms. J. Hazard. Mater. 2018, 342, 401407.

(40) Lahti, M.; Oikari, A. Vertical distribution of pharmaceuticals in lake sediments-citalopram as potential chemomarker. Environ. Toxicol. Chem. 2012, 31, 1738-1744.

(41) Shahid, N.; Becker, J. M.; Krauss, M.; Brack, W.; Liess, M. Pesticide Body Burden of the Crustacean Gammarus pulex as a Measure of Toxic Pressure in Agricultural Streams. Environ. Sci. Technol. 2018, 52, 7823-7832.

(42) Groh, K. J.; Carvalho, R. N.; Chipman, J. K.; Denslow, N. D.; Halder, M.; Murphy, C. A.; Roelofs, D.; Rolaki, A.; Schirmer, K.; Watanabe, K. H. Development and application of the adverse outcome pathway framework for understanding and predicting chronic toxicity: I. Challenges and research needs in ecotoxicology. Chemosphere 2015, 120, 764-777. 